\title{
Experimental and Numerical Heat Transfer Analyses of Exhaust Region of Reciprocating Compressor
}

\author{
Mehmet Onur Dincer, Kemal Sarioglu, and Husnu Kerpicci
}

\begin{abstract}
Efficiency of hermetic reciprocating compressors, which are used in household refrigerators, is subjected to thermodynamic, mechanical and electrical losses. Heat transfer analyses reveal reference points that involve improvement of the compressors. A proper understanding of heat transfer and temperature distribution of various components in compressor helps in determining the parts geometry and materials selection. However, the temperature of each compressor component is affected by several phenomena that act simultaneously, making the temperature distribution harder to predict.

This paper presents computational thermal analysis of components of a reciprocating compressor and comparison of the results with the measured data. Especially influence of component materials of exhaust region is investigated. Analyses are carried out by commercially available CFD code with use of temperature, mass flow rate and pressure values as boundary conditions which were obtained experimentally.
\end{abstract}

Index Terms-Compressor, CFD, heat transfer, insulation.

\section{INTRODUCTION}

Hermetic reciprocating compressors, which are the main energy consuming components of the refrigerators, are at the center of attention for decreasing the energy index level of refrigerators. Thermodynamic efficiency which still requires improvements, determines the performance of the compressor with mechanical and motor efficiencies, which are close to their limits. Thermodynamic efficiency is greatly associated with temperature distribution of the crankcase and so the inner gas of the compressor. Heat generation during the compression process inside the cylinder causes heat transfer between the crankcase, valve plate and cylinder head. It is seen that suction muffler gains heat from these aforementioned components which are at higher temperatures Suction muffler also gains heat from internal ambient of the compressor. Density of the refrigerant lowers due to rising temperature which reduces mass flow rate. This situation causes reduction in volumetric efficiency and cooling capacity.

Numerical and experimental studies that concern compressor thermodynamics and heat transfer phenomena are investigated by several authors in the literature. Sanvezzo J., Deschamps C. J. (2012) presented a simulation model that combines three dimensional formulations for conduction heat

Manuscript received November 20, 2013; revised March 3, 2014. This work was supported by Arcelik A.S.

M. O. Dincer is with the Arçelik Compressor Plant, Eskişehir, Turkey (e-mail: onurdincer@arcelik.com).

K. Sarioglu and H. Kerpicci are with Arçelik Research and Development Center, İstanbul, Turkey (e-mail: kemal.sarioglu@arcelik.com, husnu.kerpicci@arcelik.com). transfer in solid components and a lumped formulation for the gas [1]. Morriesen A., Deschamps C. J. (2012) reported an experimental investigation of transient fluid flow and superheating in the suction chamber, concluding that significant superheating is observed during the period in which the suction valve is closed [2]. Kara S., Oğuz E. (2010) carried out numerical and experimental thermal analysis of the crankcase for a model, where a single discharge muffler exists [3]. Nakano A., Kinjo K.. (2008) analyzed pressure changes in the suction muffler numerically [4]. Almbauer R.A., Burgstaller A., Abidin Z., Nagy D. (2006) presented a numerical model to solve the temperature field of a compressor cylinder-piston system, by considering different approaches [5]. Raja B., Sekhar S. J., Lal D. M., Kalanidhi A., (2003) have also created a numerical heat transfer model and obtained temperature distribution inside the hermetic compressor [6].

Aim of this study is to decrease heat transfer from the exhaust region to internal ambient of the compressor. Effect of usage of insulation materials on critical locations of the flow path and also influence of using different materials over the discharge pipe are investigated by CFD analyses.

\section{EXPERIMENTAL STUDIES}

Temperature distribution on the exhaust region of the compressor which is subjected to CFD analyses is investigated experimentally. Compressor, which is designed for R600a refrigerant and has a cooling capacity of $170 \mathrm{~W}$ at ASHRAE conditions, is instrumented with several T-type thin thermocouples. Locations of the thermocouples are given in Fig. 1. Temperature values are collected while the compressor is operating on a fully automated calorimeter system with conditions of $-23.3^{\circ} \mathrm{C}$ and $+54.4^{\circ} \mathrm{C}$ evaporation and condensation temperatures respectively. Subcooling, superheating and ambient temperatures were $32.2^{\circ} \mathrm{C}$.

On the exhaust path, refrigerant discharged from discharge plenum in the cylinder head, flows to the first discharge muffler through a resonator hole. After circulating in the muffler refrigerant leads to the connection pipe and passes into the second exhaust muffler and flows through the discharge and exhaust pipes. Results of the temperature measurements are given in Table I. The temperature at the entrance region of connection pipe between the mufflers is $99.2^{\circ} \mathrm{C}$. Temperature at the center of the connection pipe is measured $95.9^{\circ} \mathrm{C}$. Surface temperature of the discharge pipe decreases from $92.6^{\circ} \mathrm{C}$, near the second discharge muffler, to $80.4^{\circ} \mathrm{C}$. Heat transfer from refrigerant to crankcase and inner gas in means of conduction and convection causes approximately $18.8^{\circ} \mathrm{C}$ difference on the surface temperature 
of exhaust region pipes.

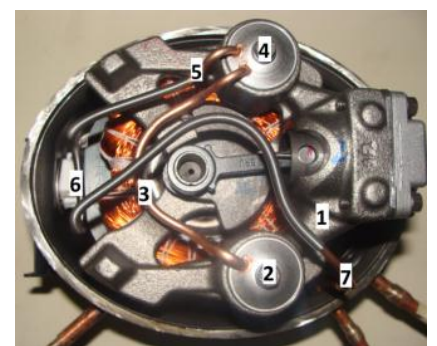

Fig. 1. Thermocouple locations on exhaust region of compressor.

TABLE I: MEASURED TEMPERATURE VALUES AT THE EXHAUST REGION
\begin{tabular}{|c|c|c|}
\hline Thermocouple no & Component & Temperature $\left({ }^{\circ} \mathrm{C}\right)$ \\
\hline 1 & Resonator hole (Flow path) & 98,5 \\
\hline 2 & Exhaust muffler 1 (Flow path) & 99,8 \\
\hline 3 & Connection pipe (Surface) & 95,9 \\
\hline 4 & Exhaust muffler 2 (Flow path) & 92,4 \\
\hline 5 & Discharge pipe (1) (Surface) & 92,6 \\
\hline 6 & Discharge pipe (2) (Surface) & 90,3 \\
\hline 7 & Exhaust pipe (Surface) & 80,4 \\
\hline
\end{tabular}

\section{NUMERICAL MODELING}

Numerical analyses were carried out to investigate the effect of material based modifications on the exhaust region. CAD model is prepared by using commercial software (NX 7.5). Mesh structure is created with ANSYS meshing software. Solution domain, which can be seen in Fig. 2, comprises approximately 750.000 tetrahedron elements. Finer mesh elements are used at required locations in order to improve mesh quality. A commercially available CFD code (ANSYS Fluent v14.0) is used for the analyses. Following assumptions are made for the CFD analyses:

- Steady state gas flow

- Incompressible flow

- Refrigerant is considered as an ideal gas

Realizable k-epsilon model is chosen for turbulence model. Discretization of momentum equations is started with first order upwind and after a couple of iterations solution method is changed to second order upwind. Energy equation is solved with second order upwind approximation. The fluid domain is divided in 6 regions due to solid structure of the compressor:

- Resonator hole (between discharge plenum and first discharge muffler)

- First discharge muffler

- Connection pipe

- Second discharge muffler

- Discharge pipe

- Exhaust pipe

Shell conduction feature is added for the solid parts named above. Shell conduction can be used to model thin sheets without the need to mesh the wall thickness in a preprocessor. When the shell conduction approach is utilized, we have the ability to easily switch on conjugate heat transfer on any wall. Boundary conditions at the inlet and outlet of the model are given as mass flow inlet at the beginning of the resonator hole and pressure outlet at the end of the exhaust pipe respectively, according to the experimental data. Mass flow rate and pressure values used for the boundary conditions are acquired from calorimeter tests. All boundary conditions and materials are given in Table II in details.

Analyses are performed for three different cases as well as the original situation. Insulating the inner side of the resonator hole with a plastic material is the subject of the first case. Same material is used inside the first suction muffler for the second case. In the third case, the effect of replacing the steel discharge pipe with a polyamide pipe on total heat transfer rate is investigated.

TABLE II: BOUNDARY CONDITIONS AND MATERIALS

\begin{tabular}{|c|c|c|c|c|c|c|}
\hline \multirow{2}{*}{ Regions } & \multirow{2}{*}{\multicolumn{2}{|c|}{ Boundary Conditions }} & \multicolumn{4}{|c|}{ Materials } \\
\hline & & & Original Case & Case 1 & Case 2 & Case 3 \\
\hline Resonator hole & \multirow{6}{*}{ 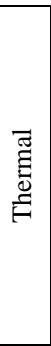 } & \multirow{3}{*}{$\begin{array}{c}\mathrm{h}: \sim 35 \mathrm{~W} / \mathrm{m}^{2} \mathrm{~K} \\
\mathrm{~T}_{\mathrm{a}}: \sim 85^{\circ} \mathrm{C}\end{array}$} & Grey cast iron & $\begin{array}{l}\text { Grey cast } \\
\text { iron }+ \\
\text { polyamide }\end{array}$ & Grey cast iron & Grey cast iron \\
\hline Exhaust muffler 1 & & & Grey cast iron & $\begin{array}{l}\text { Grey cast } \\
\text { iron }\end{array}$ & $\begin{array}{l}\text { Grey cast iron } \\
+ \text { polyamide }\end{array}$ & Grey cast iron \\
\hline Exhaust muffler 2 & & & Grey cast iron & $\begin{array}{l}\text { Grey cast } \\
\text { iron }\end{array}$ & Grey cast iron & Grey cast iron \\
\hline Connection pipe & & \multirow{3}{*}{$\begin{array}{c}\mathrm{h}: \sim 120 \mathrm{~W} / \mathrm{m}^{2} \mathrm{~K} \\
\mathrm{~T}_{\mathrm{a}}: \sim 80^{\circ} \mathrm{C}\end{array}$} & Steel & Steel & Steel & Steel \\
\hline Discharge pipe & & & Steel & Steel & Steel & Polyamide \\
\hline Exhaust pipe & & & Copper & Copper & Copper & Copper \\
\hline Inlet & \multirow{2}{*}{$\sum^{\tilde{0}}$} & $\mathrm{~m}_{\mathrm{in}}: \sim 0,5 \mathrm{~g} / \mathrm{s}_{\mathrm{in}}: 110^{\circ} \mathrm{C}$ & \multirow{2}{*}{\multicolumn{4}{|c|}{ R600a }} \\
\hline Outlet & & 7,6 bar & & & & \\
\hline
\end{tabular}

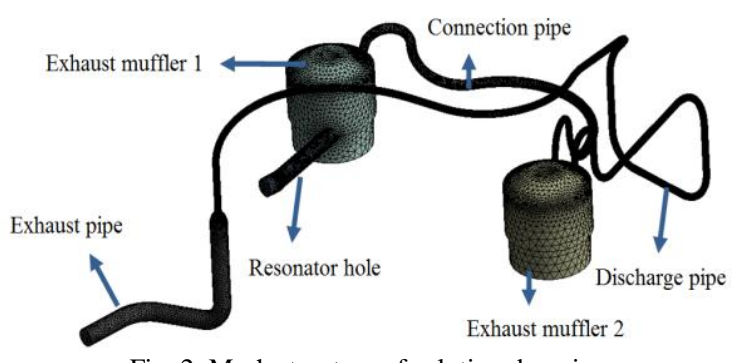

Fig. 2. Mesh structure of solution domain.
Since solid components such as crank-case, shell etc. are not included in the solution domain physically, heat transfer coefficients were used for tuning heat transfer mechanisms and temperature values on the exhaust region, in order to obtain a basis, which is similar to experimental data, to compare different cases. Heat transfer coefficients are set at resonator hole, exhaust muffler 1 and exhaust muffler 2 to order of $\sim 35 \mathrm{~W} / \mathrm{m} 2 \mathrm{~K}$ and at connection, discharge and exhaust pipes to order of $120 \mathrm{~W} / \mathrm{m} 2 \mathrm{~K}$. Temperature values 
obtained by CFD analysis for original case, case 3 and experimentally measured values on common components are given in Table III. Temperatures measured inside are denoted by $\left(^{*}\right)$. It can be seen that results are in a good agreement with measured temperature values with a maximum deviation of
$3 \%$.

Contours of outer temperature of the exhaust region are given in Fig. 3. for the original case. Remarkable changes could not be stated in temperature values and total heat transfer rates on the exhaust region for case 1 and case 2 .

TABLE III: COMPARISON OF ORIGINAL CASE WITH EXPERIMENTAL MEASUREMENTS

\begin{tabular}{|c|c|c|c|c|c|c|c|}
\hline & $\begin{array}{c}\text { Resonator } \\
\text { hole }\end{array}$ & $\begin{array}{c}\text { Exhaust } \\
\text { muffler 1 }\end{array}$ & $\begin{array}{c}\text { Connection } \\
\text { pipe }\end{array}$ & $\begin{array}{c}\text { Exhaust } \\
\text { muffler 2 }\end{array}$ & $\begin{array}{c}\text { Discharge } \\
\text { pipe (1) }\end{array}$ & $\begin{array}{c}\text { Discharge } \\
\text { pipe (2) }\end{array}$ & \begin{tabular}{c} 
Exhaust pipe \\
\hline Experimental
\end{tabular} \\
$98,5^{*}$ & $99,8^{*}$ & 95,9 & $92,4^{*}$ & 92,6 & 90,3 & 80,4 \\
\hline Original case & 101,9 & 100 & 99,2 & 94,6 & 95,1 & 93,3 & 82,8 \\
\hline $\begin{array}{c}\text { Polyamide discharge pipe } \\
\text { (Case 3) }\end{array}$ & 101,8 & 100,7 & 99,5 & 95,1 & 87,3 & 87,1 \\
\hline
\end{tabular}

Polyamide discharge pipe (case 3) reveals lower temperatures and decrease in total heat transfer rate up to $12 \%$. Experimental temperature values and temperature values obtained from CFD analyses in original case, case 3 and on the surfaces of exhaust region components are compared in Fig. 4. Case 3, in which material of the discharge pipe is set as polyamide, leads refrigerant to leave the compressor at higher temperature while transferring less heat to the adjacencies. This causes approximately $7^{\circ} \mathrm{C}$ lower temperatures on the surface of the discharge pipe compared to the original case.

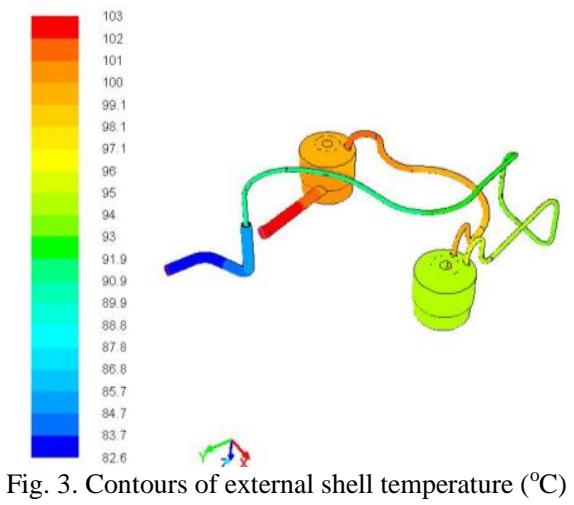

\section{CONCLUSION}

In this study, applications of three different insulation concepts were investigated numerically after refining the numerical model to realistic circumstances. Motivation of insulating particular regions is to reduce total heat transfer from whole exhaust region to the inner gas of the compressor. It is clear that inner gas is one of the common heat sources for suction gas inside the suction muffler, which causes decrease in volumetric efficiency. CFD analyses exposed that, using a plastic originated material inserted inside the resonator hole and first exhaust muffler does not deduce significant effect on heat transfer rate. The reason of this situation can be defined as; reducing heat transfer from the refrigerant at the former sections of the exhaust path leads other sections to higher temperatures. Reducing heat transfer on some sections, while increasing on others, lowers impact of the insulation. On the other hand, insulating the end region of the exhaust path especially by using materials with lower thermal conductivities as discharge pipe as investigated in case 3 , results in $12 \%$ decrease of total heat transfer rate for the whole region. It is concluded that, end regions of the exhaust path are the most important locations for effective insulation.

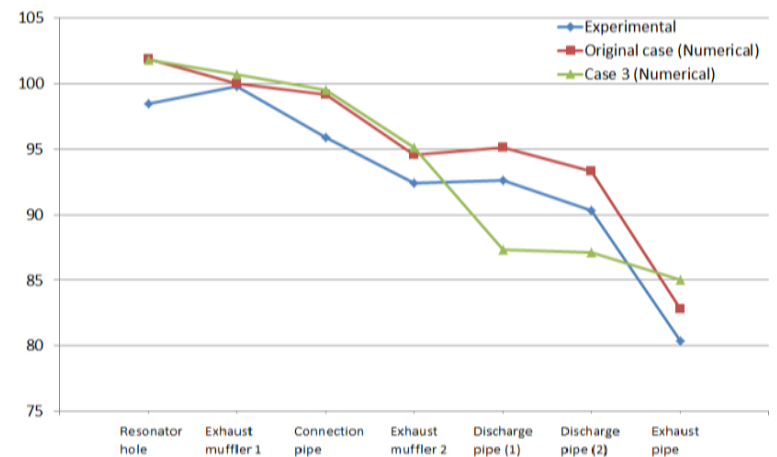

Fig. 4. Comparison of case 3 with the original case and experimental measurements.

\section{ACKNOWLEDGMENT}

The authors would like to express their sincere appreciation to Arçelik A.Ş.

\section{REFERENCES}

[1] J. Sanvezzo and C. J. Deschamps, "A Heat transfer model combining differential and integral formulations for thermal analysis of reciprocating compressors," in Proc. Int. Compressor Engineering Conference at Purde., 2012.

[2] A. Morriesen and C. J. Deschamps, "Experimental investigation of transient fluid flow and superheating in the suction chamber of a refrigeration reciprocating compressor," Applied Thermal Engineering, vol. 41, pp 61-70, 2012.

[3] S. Kara and E. Oğuz, "Thermal analysis of a small hermetic reciprocating compressor," in Proc. Int. Compressor Engineering Conference at Purdue, 2010.

[4] A. Nakano and K. Kinjo, "CFD applications for development of reciprocating compressor," in Proc. Int. Compressor Engineering Conference at Purdue, 2008.

[5] R. A. Almbauer, A. Burgstaller, Z. Abidin, and D. Nagy, "3-Dimensional simulation for obtaining the heat transfer correlations of a thermal network calculation for a hermetic reciprocating compressor," in Proc. Int. Compressor Engineering Conference at Purdue, 2006.

[6] B. Raja, S. J. Sekhar, D. M. LAl, and A. Kalanidhi, "Numerical model for thermal mapping in a hermetically sealed reciprocating refrigerant compressor," International Journal of Refrigeration, vol. 26, issue 6, pp. 652-658, 2003.

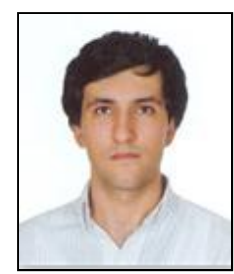

Mehmet Onur Dinçer was born in Istanbul, Turkey, 1989. He received his BSc. in mechanical engineering from Kocaeli State University, Kocaeli, Turkey in 2011. He received his MSc in mechanical engineering from Istanbul Technical University, Istanbul, Turkey, 2014. His research interests lie in the area of computational fluid dynamics, heat 
transfer and compressor technologies.

He worked in the Research and Development Center of Arçelik A.S during his post graduate studies. He is currently working in R\&D Department of Arçelik Compressor Plant in Eskişehir,

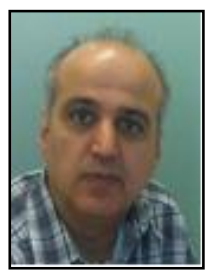

Kemal Sarıoğlu was born in Istanbul, Turkey, 1966. $\mathrm{He}$ obtained BSc. degree in mechanical engineering from Istanbul Technical University, Istanbul, Turkey, in 1988. He received MSc degree in mechanical engineering from Istanbul Technical University, Istanbul, Turkey, in 1990 and $\mathrm{PhD}$ degree in mechanical engineering from Istanbul Technical University, Istanbul, Turkey in1966. His research interests lie in the area of turbomachinery, reciprocating compressors, solidification, drying systems and computational fluid dynamics.

$\mathrm{He}$ worked as an assistant professor at İstanbul Technical University in Istanbul then worked as a project manager at Kibar Holding. He is working as a research specialist at R\&D Center of Arcelik A.S., Istanbul/Turkey.

Previously he studied on the numerical investigation of $3 \mathrm{~d}$ flow in pumps; he is currently working on reciprocating compressors and fan design used in household appliances.

K. Sarioglu is a member of Turkish Mechanical Engineers Association. K. Sarioglu is the best project owner of Koc Holding Group and received awards from the projects he leaded.

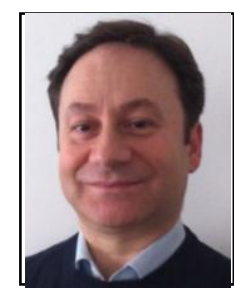

Husnu Kerpicci was born in Istanbul, Turkey, 1966. He got BSc. Degree in mechanical engineering from Istanbul Technical University, Istanbul, Turkey, in 1987. He obtained MSc degree in mechanical engineering from Bogazici University, Istanbul Turkey, in 1991 and $\mathrm{PhD}$ degree from RWTH Aachen, Institute for Steam and Gas Turbines in 2002. His research interests lie in the area of reciprocating compressors, refrigeration systems, heat exchanger, computational fluid dynamics and tribology.

He worked as a research assistant at Bogazici University in Istanbul then at Institute for Gas and Steam Turbines in Germany. He is working as a technical leader at R\&D Center of Arcelik A. S., Istanbul/Turkey.

Previously he studied on the condensation phenomena in low pressure steam turbines; he is currently working on reciprocating compressors and refrigeration systems and journal bearing design.

Dr. Kerpicci is a member of ASME. Dr. Kerpicci is the best patent owner and had best inventor award at Arcelik A.S. in 2007. 